\title{
Heart Histopathology and Oxidative Features in Diabetic Rats and Protective Effects of Oleuropein
}

\author{
Hedya Jemai*, Sami Sayadi \\ Laboratoire des Bioprocédés, Pôle d'Excellence Régionale AUF, (PER-LBP) Centre de Biotechnologie de Sfax, \\ Sfax, Tunisie \\ Email: "hedya.jemai@gmail.com
}

Received 24 April 2015; accepted 5 June 2015; published 9 June 2015

Copyright (C) 2015 by authors and Scientific Research Publishing Inc.

This work is licensed under the Creative Commons Attribution International License (CC BY). http://creativecommons.org/licenses/by/4.0/

\section{(c) (i) Open Access}

\section{Abstract}

Diabetes induced cardiac dysfunction and lesions are nowadays confirmed. In fact, Diabetes is a chronic metabolic disease, which is associated with oxidative stress and hyperglycaemia which have direct toxic effects on cardio-myocytes. Olive leaves extract compounds, such as Oleuropein, have been used in many therapeutic and preventive cases. The present study is designed to evaluate the effect of Oleuropein as antioxidant on the heart histological and oxidative features in diabetic rats. Diabetes was induced by alloxan at $180 \mathrm{mg} / \mathrm{kg}$ b.w by intra-peritoneal method once. Four weeks Oleuropein rich olive leaves administration restore significantly the heart histological alteration established by diabetes and enhanced the cardiac antioxidant potential.

\section{Keywords}

Antioxidants, Diabetes, Heart, Heart Histology, Oleuropein

\section{Introduction}

Diabetes is a chronic metabolic disease associated with hyperglycemia and oxidative stress which generally causes several tissue damage and subsequently degenerative complications in many organs such as the heart [1]. In fact, cardiovascular complications are one of the major causes of death in diabetes mellitus [2]. The hyperglycemia as well the physiological oxidative parameters induced cardiac dysfunction and lesions via direct toxic effects on cardio-myocytes. Subsequently natural active principle might restore diabetes cardiac complications.

\footnotetext{
${ }^{*}$ Corresponding author.
}

How to cite this paper: Jemai, H. and Sayadi, S. (2015) Heart Histopathology and Oxidative Features in Diabetic Rats and Protective Effects of Oleuropein. Advances in Bioscience and Biotechnology, 6, 383-389. 
Moreover, antioxidants play an important role to protect against damage by reactive oxygen species and their role in diabetes has been evaluated. It nowadays confirmed the implication of the oxidative stress in the diabetes complication and pathological symptoms [3]. Therefore antioxydants are more and more used and required. The active principles of many plant species are isolated for direct use as drugs, lead compounds or pharmacological agents [4]. Traditional plant medicines or herbal formulations might offer a natural key to unlock diabetic complications [5]. Antioxidants play an important role to protect against damage by reactive oxygen species. Many plant extracts and products were shown to possess significant antioxidant activity [6]. Olive leaves are considered to be a potential source of antioxidants, allowed with many biological activities, among them Oleuropein which showed a large antidiabetic effects. In this part, we are interested in the beneficial effects of Oleuropein in the heart of diabetic rats. In fact, Diabetes affects a great number of organs and tissues such as the kidneys, the heart, the eyes and the spleen. This is the first study which focuses on the protective effects of Oleuropein in the heart tissue and its antioxidant parameters in diabetic rats.

\section{Material and Methods}

\subsection{Oleuropein Rich Olive Leaves Extract Preparation}

$50 \mathrm{~g}$ of olive leaf powder of Chemlali olive leaves dried and powdered extracted by a mixture of methanol and water $(200 \mathrm{ml}, 4: 1 \mathrm{v} / \mathrm{v})$. The mixture was left to stand under agitation for $24 \mathrm{~h}$ and then was filtered. The extract was concentrated by evaporation to dryness at $40^{\circ} \mathrm{C}$, and the residue obtained was stored in glass vials, at $0{ }^{\circ} \mathrm{C}$ in the dark until HPLC analysis. Four gram (4 g) sample was dissolved in methanol (10 ml) and extracted three times with ethyl acetate (Prolabo, France) $(40 \mathrm{ml})$ to prepare the oleuropein-rich extract.

\subsection{Diabetes Induction}

Diabetes was induced in rats by a single intra-peritoneal injection of freshly prepared alloxan solution in normal saline at a dose of $180 \mathrm{mg} / \mathrm{kg}$ body weight [7]. Adult male Wistar rats (180 $\pm 15 \mathrm{~g})$ obtained from the Central Pharmacy Tunisia, were used. Diabetes was induced after 5 days and it was confirmed by the presence of glucosuria.

\subsection{Animals and Treatment}

Adult male Wistar rats, with body weight of 165 - $195 \mathrm{~g}$, were used in this study. The animals were kept in an environmentally controlled breeding room (temperature: $20^{\circ} \mathrm{C} \pm 2{ }^{\circ} \mathrm{C}$, humidity: $60 \% \pm 5 \%, 12 \mathrm{~h}$ dark/light cycle). All rats had access to a standard laboratory diet (SICO, Sfax, Tunisia) and fasted overnight before blood and tissue collection. The handling of the animals was approved by the local Ethical Committee for the care and use of laboratory animals. The rats were divided into 3 groups consisting of 10 ones each. Group Control (normal control) consisted of normal rats. Group Diabetic served as positive control (diabetic control) and group Oleuropein which received $16 \mathrm{mg} / \mathrm{kg}$ of body weight of oleuropein occurring in the olive leaves extract which was dissolved in drinking water. The duration of the treatment was 4 weeks. At the end of the experimental period, the rats were killed by decapitation. Organ were removed and rinsed with physiological saline solution. All samples were stored at $-80^{\circ} \mathrm{C}$ until analysis.

\subsection{Heart Catalase Activity}

Catalase (CAT) activity was evaluated in heart tissue. The preparation of the enzyme source fraction was as follows. One gram of heart tissue was homogenized in $10 \mathrm{~mL}$ of $\mathrm{KCl}(1.15 \%)$ and centrifuged at $7740 \mathrm{~g}$ for $15 \mathrm{~min}$. The supernatants were removed and stored at $-80^{\circ} \mathrm{C}$ for analysis. The protein content in supernatant was measured according to the method of Bradford [8] using bovine serum albumin as standard. CAT activity was measured using the method of Regoli and Principato [9]. Briefly, $20 \mu \mathrm{L}$ of the supernatant was added to a cuvette containing $780 \mu \mathrm{L}$ of a $50 \mathrm{M}$ potassium phosphate buffer $(\mathrm{pH} 7.4)$, and then the reaction was initiated by adding $200 \mu \mathrm{L}$ of $500 \mathrm{mM} \mathrm{H}_{2} \mathrm{O}_{2}$ to make a final volume of $1.0 \mathrm{~mL}$ at $25^{\circ} \mathrm{C}$. The decomposition rate of $\mathrm{H}_{2} \mathrm{O}_{2}$ was measured at $240 \mathrm{~nm}$ for $1 \mathrm{~min}$ on a spectrophotometer. A molar extinction coefficient of $0.0041 \mathrm{mM}^{-1} \cdot \mathrm{cm}^{-1}$ was used to determine the CAT activity. The activity was defined as the micromoles of $\mathrm{H}_{2} \mathrm{O}_{2}$ decrease per milligram of protein per minute. 


\subsection{Thiobarbituric Acid-Reactive Substances (TBARS) Assay}

TBARS are the marker of lipid peroxidation. Their concentration was measured referring to Park et al. [10] assay. Briefly, $200 \mu \mathrm{L}$ of a $10 \%(\mathrm{w} / \mathrm{v})$ solution of the tissue homogenate was mixed with $600 \mu \mathrm{L}$ of distilled $\mathrm{H}_{2} \mathrm{O}$ and $200 \mu \mathrm{L}$ of $8.1 \%(\mathrm{w} / \mathrm{v}) \mathrm{SDS}$, and then incubated at room temperature for $5 \mathrm{~min}$. The reaction mixture was heated at $95^{\circ} \mathrm{C}$ for $1 \mathrm{~h}$ after the addition of $1.5 \mathrm{~mL}$ of $20 \%$ acetic acid (pH 3.5) and $1.5 \mathrm{~mL}$ of $0.8 \%$ (w/v) TBA. Later, the mixture had cooled and $1.0 \mathrm{~mL}$ of distilled water and $5.0 \mathrm{~mL}$ of a butanol/pyridine (15:1) solution were added under agitation using a vortex. This solution was centrifuged at $1935 \mathrm{~g}$ for $15 \mathrm{~min}$, and the resulting coloured layer was measured at $532 \mathrm{~nm}$. The concentrations were determined using a malondialdehyde (MDA) standard curve.

\subsection{Histopathological Study}

The tissue samples in 10\% buffered formalin were sliced to approximately $1 \mathrm{~cm}$ thick, and placed into the cassettes. Then, the cassettes are placed in a tissue processor machine, which comprise of dehydration with alcohol, clearing with xylene and wax, and impregnating process automatically overnight (14 hours). The cassettes were embedded in molten paraffin, which later cooled down to formed blocks of paraffin. Each block was trimmed then sectioned about $5 \mu \mathrm{m}$ by using a microtome. Hematoxylin and Eosin ( $\mathrm{H} \& \mathrm{E})$ dye, which mounted with DPX for microscopic observations.

\subsection{Statistical Analysis}

Results were presented as mean \pm standard deviation (S.D.). The data follow a normal distribution. A two-way analysis of variance was performed using a Student's t-test on Microsoft Excel statistical software (Microsoft Corporation, Microsoft Office Excel 2003, Redmond, WA). The values were considered significantly different when the $p$-value was lower than 0.05 .

\section{Results}

\subsection{Olive Leaves Extracts Characterization}

The olive leaves extracts phenolic composition was analysed via HPLC (Figure 1). Figure 1 shows a concentration of oleuropein reaching up $2 \mathrm{~g} / 100 \mathrm{~g}$ dry weight. The identification of oleuropein was based on comparison of the chromatographic retention time and UV absorbance spectra with those of an authentic standard. The analysis was confirmed using an LC-MS system operating in positive mode which showed a correspondence of the mass spectrum of the extract with the known fragmentation scheme for oleuropein.

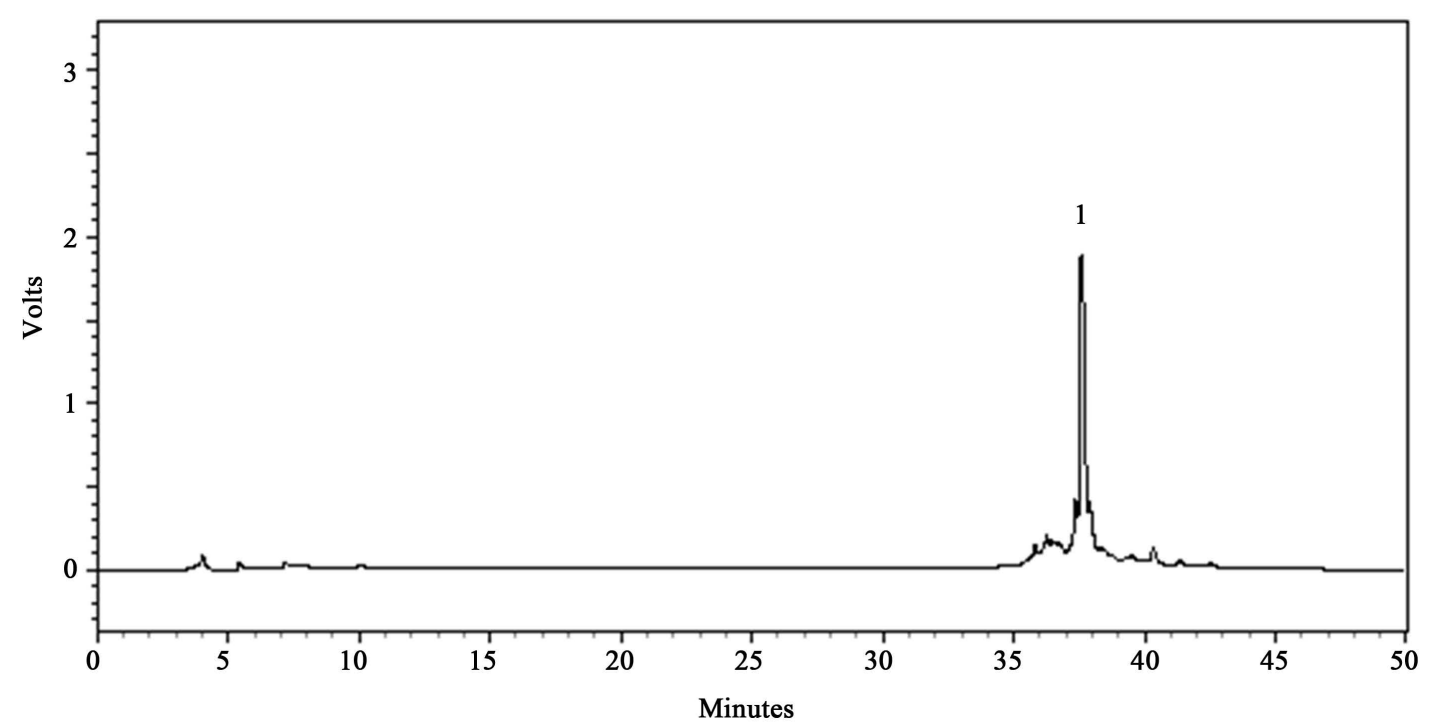

Figure 1. HPLC chromatogram at $280 \mathrm{~nm}$ of olive leaf extracts based on Oleuropein. (1: Oleropein). 


\subsection{Heart Catalase Activity}

Catalase (CAT) antioxidant enzyme activity in the heart was significantly decreased in diabetic rats compared with its values in control ones (Figure 2). In fact catalase activity in control rats was $99.16 \mu \mathrm{mol} / \mathrm{min} / \mathrm{mg}$ of protein, whereas it was just 39.43 in Diabetic rats. Oleuropein administration for 4 weeks significantly restored the catalase activity to reach a value of $82.98(p<0.05)$.

\subsection{Heart Lipid Peroxidation}

The lipid peroxidation evaluated by thiobarbituric acid reactive substances (TBARS) levels were significantly increased $(p<0.05)$ in the heart of diabetic rats compared to the normal control group. This fact confirmed the established oxidative stress in the cardiomyocytes associated with Diabetes. The administration of oleuropein significantly reduced the TBARS concentrations $(p<0.05)$ (Figure 3).

\subsection{Histology of the Cardiac Tissue}

Under Hematoxiline and Eosine staining, Control group showed single, oval and centrally located nuclei of cardiomyocytes with regularly arranged cardiac myofibres (Figure 4(a)). A similar pattern could be found in Oleuropein group. However, nuclei of the cardiomyocytes in Diabetic group (Figure 4(b)) showed deformation in sizes and shapes. Moreover, the cardiac myofibres in this group was found to be in disarrayed pattern compared to Control group. Oleuropein group was found to possess fewer severe histological changes in the cardiac tissues compared to the Diabetic group (Figure 4(c)).

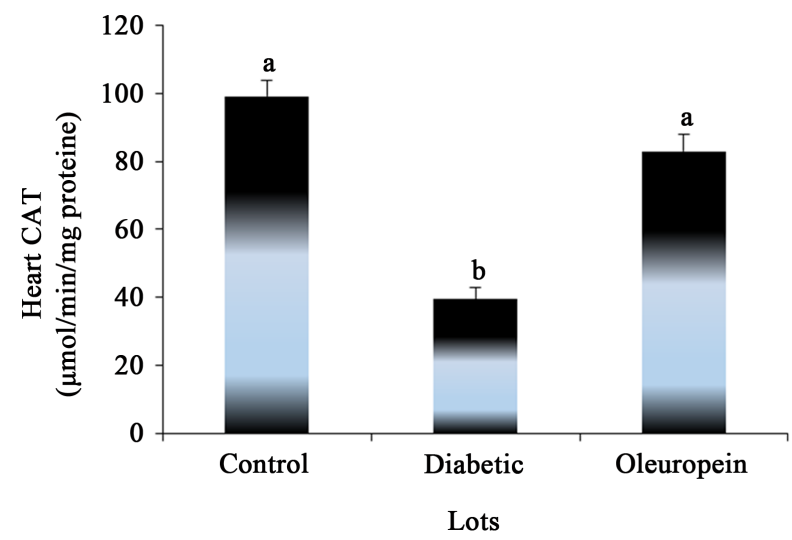

Figure 2. Oleuropein restores the Heart catalase antioxidant enzyme activity. Control: normal control; Diabetic: diabetic control; Oleuropein: Diabetic + Oleuropein.

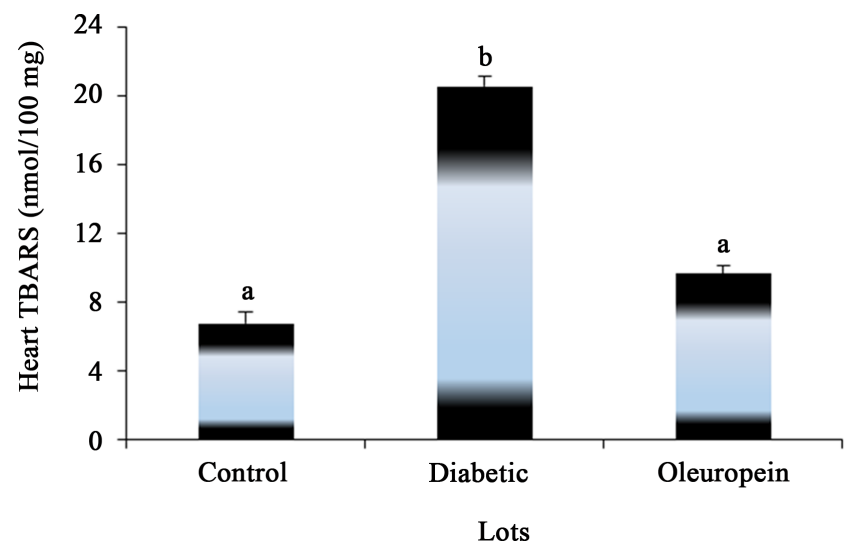

Figure 3. Effect of Oleuropein on the Heart TBARS (lipid peroxidation values). Control: normal control; Diabetic: diabetic control; Oleuropein: Diabetic + Oleuropein. 


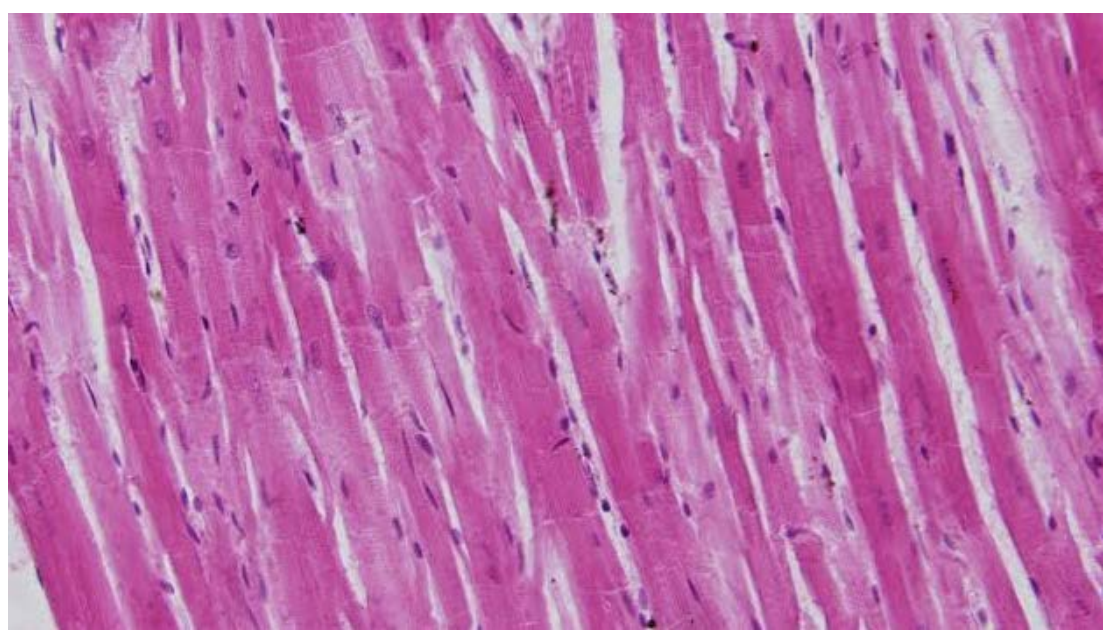

(a)

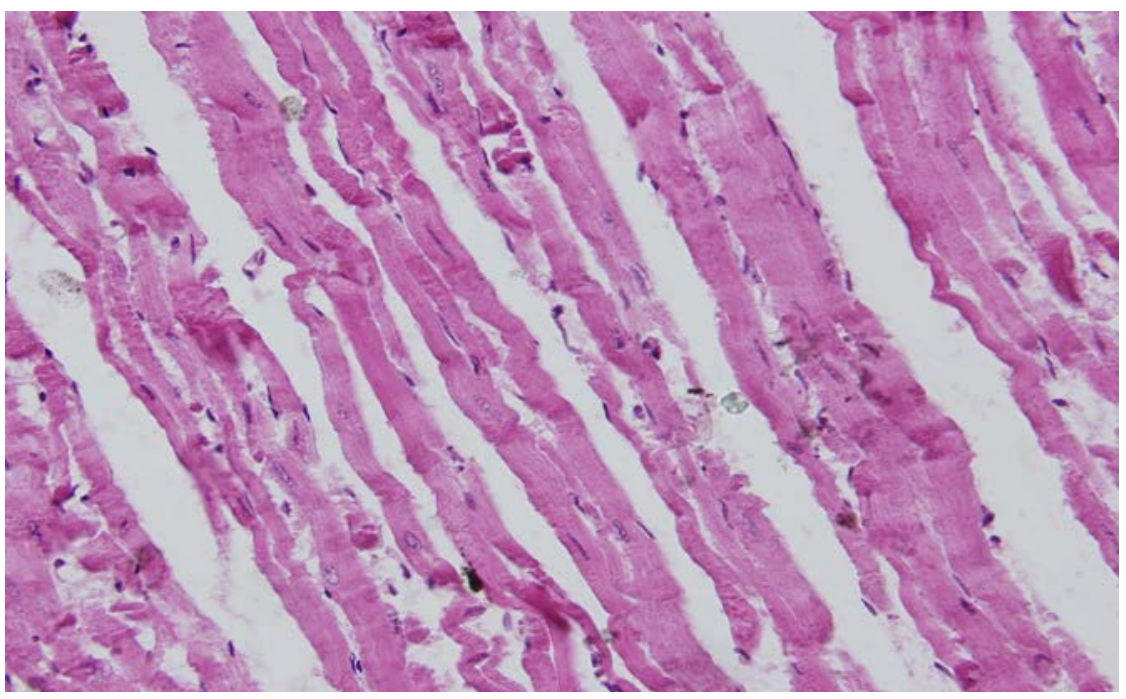

(b)

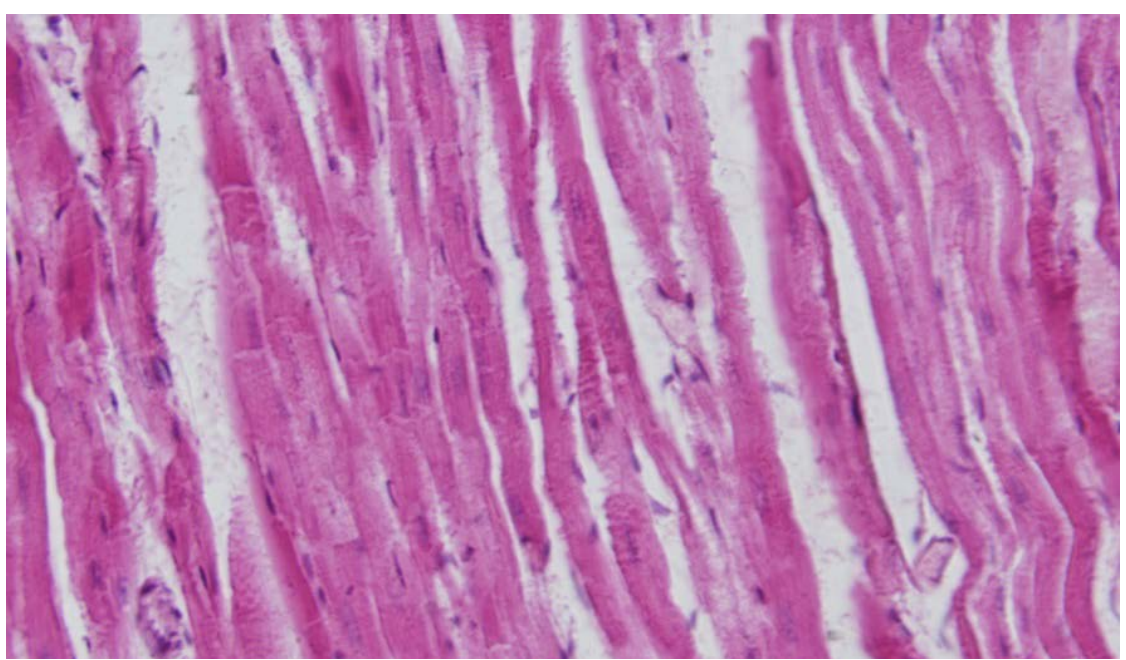

(c)

Figure 4. Histological organization of the Heart of control rats (a), diabetic rats (b) and diabetic rats with Oleuropein intake (hematoxylin-eosin, H \& E staining, 400×). 


\section{Discussion}

We studied histological features of diabetes lesions and modifications in the heart and oxidative stress establishment. Furthermore we investigate the curative effect of Oleuropein which known to be a powerful antioxidant [11]. In the present study, the alloxan induced diabetic rats are used as a type 1 models which are characterized by the uncontrolled hyperglycaemia [12]. Diabetes mellitus, is a syndrome resulting from a variable interaction of genetic and environmental factors. It is characterized by abnormalities in insulin secretion and in its receptor interaction affecting metabolism and many vital organs [13]. The present study was under taken with the objective of exploring the Oleuropein antioxidant and cardiac protective effects in diabetic rats. Recent studies have suggested that prevalence of Heart dysfunctions and lesions are more frequent and severe in patients with diabetes. In fact Diabetes is an independent risk factor for cardiac failure [14]. It has been found that oxidative stress is associated with the molecular mechanism of the decreased insulin biosynthesis and secretion. In fact diabetic rats showed a decreased activity of catalase which is responsible for the detoxification of the free radical implicated in the oxidative tissue lesions. Subsequently, the diabetic rats showed increased values of lipid peroxidation parameters which confirm the heart necrosis and lesions. Diabetes affected many metabolisms and caused considerable lesions in numerous vital organs. Indeed, it was suggested that some tissues may be more susceptible to oxidative stress than other ones [15] [16].

In the control group, heart slides under the light microscope show that the nuclei of the cardio-myocytes were single, oval, prominent and centrally located as observed. Contrariwise, in the diabetic rats many alterations were noticed in the cardiomyocyte form and disposition. In fact the histological features of the cardiac tissue were disturbed in alloxan-induced diabetic rats. Oxidative inflammatory histological changes in cardiac tissues indicated the myocardial injury such as deformation of nuclei of cardiomyocytes and disarrangement or disordered cardiac myofibrils. The structural cardiomyocytes change was probably due to the degeneration of the structural protein in mitochondria of the cytoplasm that occurred in protein degradation related to Diabetes.

In diabetic rats, a decrease of cardio-myocytes nuclei sizes was observed. This modification was found previously associated with diabetes. Furthermore we observed disarrayed cardiac myofibres. These findings are with concordance with previous studies [2] [17]. These modifications might be in relation with insulin deficiency which can be in indirect disruption in the cardiac myofibrils [12].

The administration of Oleuropein for four weeks at $16 \mathrm{mg} / \mathrm{kg} \mathrm{b} \mathrm{w}$, lead to a normal histological organization in the heart cells and nuclei. The oleuropein antioxidant activity may have prevented the oxidative damage at the myocardium in alloxan-induced diabetic rats. Our results showed that treatment with olive leave extract decreased the cardiac damage in diabetic rats. In the other hand, hyperglycaemia leads to the over-production of free radicals [18]. Our results show decreased activities of heart antioxidant enzymes catalase (CAT) and increased TBARS level in diabetic rats compared with the normal controls. These results are in concordance with other findings showing that hyperglycaemia is usually combined with oxidative stress establishment [19]. All these antioxidant system depletions were restored by the administration of Oleuropein at $16 \mathrm{mg} / \mathrm{kg}$ b. w a long of four weeks. This fact can be explained by the fact that Oleuropein, like the majority of biophenols could scavenge free radical circulating and increased the expression the antioxidant enzymes such as catalase at the transcriptional level [20].

\section{Conclusion}

The goal of this study was to evaluate the effect of Oleuropein occurred in olive leaves extracts on the heart histological lesions in alloxan induced diabetic rats and on the oxidative damages associated with diabetes. In conclusion, treatment with Oleuropein rich extract had a beneficial effect on alloxan induced diabetic rats. Treatment with Oleuropein at $16 \mathrm{mg} / \mathrm{kg}$ b w maintained the histological integrity of the cardiac tissues by reducing the degenerative changes in the myocardium, enhanced the antioxidant enzymes and subsequently significantly minimize the lipid peroxidation.

\section{References}

[1] Adequate, E. (2001) Diabetes Mellitus-Multifactor in Aetiology and Global in Prevalence. Archives of Physiology and Biochemistry, 109, 197-199. http://dx.doi.org/10.1076/apab.109.3.197.11588

[2] Chi, T.Z., Lin, T.S., Das, S. and Zakaria, Z. (2012) Histological Changes in the Heart and the Proximal Aorta in Expe- 
rimental Diabetic Rats Fed with Piper Sarmentsoum. The African Journal of Traditional, Complementary and Alternative Medicines, 9, 396-404.

[3] Jemai, H., Bouaziz, M., Fki, I., El Feki, A. and Sayadi, S. (2008) Hypolipidimic and Antioxidant Activities of Oleuropein and Its Hydrolysis Derivative-Rich Extracts from Chemlali Olive Leaves. Chemico-Biological Interactions, 176, 88-98. http://dx.doi.org/10.1016/j.cbi.2008.08.014

[4] Fabricant, D.S. and Farnsworth, N.R. (2001) The Value of Plants Used in Traditional Medicine for Drug Discovery. Environmental Health Perspectives, 109, 69-75. http://dx.doi.org/10.1289/ehp.01109s169

[5] Nammi, S., Boini, M.K., Lodagala, S.D. and Behara, R.B. (2003) The Juice of Fresh Leaves of Catharanthus roseus Linn Reduces Blood Glucose in Normal and Alloxan Diabetic Rabbits. BMC Complementary and Alternative Medicine, 3, 4. http://dx.doi.org/10.1186/1472-6882-3-4

[6] Sabu, M.C. and Kuttan, R. (2002) Antidiabetic Activity of Medicinal Plants and Its Relationship with Their Antioxidant Property. Journal of Ethnopharmacology, 81, 155-160. http://dx.doi.org/10.1016/S0378-8741(02)00034-X

[7] Prashant, S., Namakkal, H.S., Rajasekaran, T.S. and Chandra, T. (2005) Effects of the Antioxidant Properties of Millet Species on Oxidative Stress and Glycemic Status in Alloxan-Induced Rats. Nutrition Research, 25, 1109-1120. http://dx.doi.org/10.1016/j.nutres.2005.09.020

[8] Bradford, M.M. (1976) A Rapid and a Sensitive Method for the Quantification of Microgram Quantities of Protein Utilizing the Principle of Protein-Dye Binding. Analytical Biochemistry, 72, 248-254. http://dx.doi.org/10.1016/0003-2697(76)90527-3

[9] Regoli, F. and Principato, G. (1995) Glutathione, Glutathione-Dependant and Antioxidant Enzymes in Mussel, Mytilus Gallopro Vincilis Exposed to Metals in Different Field and Laboratory Condition. Implications for a Proper Use of Biochemical Markers. Aquatic Toxicology, 31, 143-164. http://dx.doi.org/10.1016/0166-445X(94)00064-W

[10] Park, S.Y., Bok, S.H., Jeon, S.M., Park, Y.B., Lee, S.J., Jeong, T.S. and Choi, M.S. (2002) Effect of Rutin and Tannic Acid Supplements on Cholesterol Metabolism in Rats. Nutrition Research, 22, 283-295. http://dx.doi.org/10.1016/S0271-5317(01)00398-0

[11] Jemai, H., Bouaziz, M., Fki, I., El Feki, A. and Sayadi, S. (2008) Hypolipidimic and Antioxidant Activities of Oleuropein and Its Hydrolysis Derivative-Rich Extracts from Chemlali Olive Leaves. Chemico-Biological Interactions, 176, 88-98.

[12] Nemoto, O., Kawaguchi, M., Yaoita, H., Miyake, K., Maehara, K. and Maruyama, Y. (2006) Left Ventricular Dysfunction and Remodeling in Streptozotocin-Induced Diabetic Rats. Circulation Journal, 70, 327-334. http://dx.doi.org/10.1253/circj.70.327

[13] Ghosh, S. and Surawanshi, S.A. (2001) Effect of Vinca rosea Extracts in Treatment of Alloxan Diabetes in Male Albina Rats. Indian Journal of Experimental Biology, 8, 748-759.

[14] Jagdish, K. and Shah, N.J. (2010) Effect of Valsartan on Isoproterenol Induced Myocardial Infarction and Histopathological in Heart in Diabetic Rats. Journal of Pharmaceutical, Chemical and Biological Sciences, 1, 275.

[15] Evans, J.L., Goldfine, I.D., Maddux, B.A. and Grodsky, G.M. (2003) Are Oxidative Stress-Activated Signaling Pathways Mediators of Insulin Resistance and Beta-Cell Dysfunction? Diabetes, 52, 1-8. http://dx.doi.org/10.2337/diabetes.52.1.1

[16] Robertson, R.P. (2006) Oxidative Stress and Impaired Insulin Secretion in Type 2 Diabetes. Current Opinion in Pharmacology, 6, 615-619. http://dx.doi.org/10.1016/j.coph.2006.09.002

[17] Cosyns, B., Droogmans, S., Weytjens, C., Lahoutte, T., Van Camp, G., Schoors, D., Franken, P.R. (2007) Effect of Streptozotocin-Induced Diabetes on Left Ventricular Function in Adult Rats: An in Vivo Pinhole Gated SPECT Study. Cardiovascular Diabetology, 6, 30-37. http://dx.doi.org/10.1186/1475-2840-6-30

[18] Baynes, J.W. (1991) Role of Oxidative Stress in Development of Complications in Diabetes. Diabetes, 40, 405-412. http://dx.doi.org/10.2337/diab.40.4.405

[19] Duzguner, V. and Kaya, S. (2007) Effect of Zinc on the Lipid Peroxidation and the Antioxidant Defense Systems of the Alloxan-Induced Diabetic Rabbits. Free Radical Biology \& Medicine, 42, 1481-1486. http://dx.doi.org/10.1016/j.freeradbiomed.2007.02.021

[20] Vina, J., Borras, C., Gomez-Cabrera, M.C. and Orr, W.C. (2006) Role of Reactive Oxygen Species and (Phyto) Oestrogens in the Modulation of Adaptive Response to Stress. Free Radical Research, 40, 111-119. http://dx.doi.org/10.1080/10715760500405778 